\title{
A methodological note on direct tests of the effectlveness of positional cues in serial learning
}

JOHN R. HESLIP, University of Kansas, Lawrence, Kans. 66044

In direct tests of the effectiveness of cues that can be ordered conceptually along some dimension such as spatial or ordinal position, $S$ is presented with a test cue and asked to respond with an item from the corresponding position in the serial list. Although it is assumed that $S$ uses only the test cue to mediate recall, it is possible that he is able to locate the correct response by covertly reciting and counting a sequence of items from the list. Three groups of $13 \mathrm{Ss}$ were used to show that a recitation confounding can occur, and that it can be eliminated with instructions and a 3 sec response time-limit. The results also showed that the test method is a consistent measuring device over different degrees of acquisition.

Often a series of items can be ordered conceptually along some dimension. Ebenholtz (1965) has suggested that this conceptual dimension may act as a cue in serial learning. The dimensional attribute may be spatial position, ordinal numbers, line lengths, reflectance, or any other attribute that can be graded from least to most or first to last.

Schulz (1955) has tested the hypothesis directly using ordinal numbers and Heslip \& Epstein (in press) have tested it directly for spatial positions. In a direct test, $\mathrm{S}$ learns only one serial list. The effectiveness of the proposed cue is tested by presenting $S$ with a cue from the ordered dimension and asking him to respond with the corresponding serial item. For example, E might present the number "six" and S would try to respond quickly with the six th item in the serial list. It is assumed that $S$ uses only the test cue to mediate recall; however, it is possible that he might respond to the number "six" by covertly reciting the first six items in the list and then overtly emitting the sixth item. Schulz tried to eliminate this potential confounding by requiring $S$ to respond rapidly to the test item. However, there is no independent evidence to indicate how much time is required to covertly recite a sequence of items under these conditions of testing, so there is no way of knowing if immediate responding eliminates the possibility of recitation. The present study was designed to investigate this question.

\section{METHOD}

Each $S$ received six memory-drum paced serial anticipation trials with a practice list followed by presentation of an experimental list of 13 words high in meaningfulness and frequency of occurrence (Noble \& Parker, 1960). Each word was presented for $2 \sec$ with a $4 \sec$ intertrial interval. $S$ was then confronted with a board divided into a series of 13 squares corresponding to the series of words in the list. The words, printed on pieces of cardboard, were presented to $S$ one at a time in random order, and the time required to place each word in a square on the board was recorded. Each word was removed from the board before the next one was presented.

Twenty-six Ss learned the list to a criterion of one-perfect-trial (OPT group). Every other $S$ tested was assigned to one of two subgroups for the position placement task. One group (OPT-position) was told to place each word immediately on the spatial array in the location that looked like it represented the word's location in the list. They were told to use the spatial array as their only guide in placing each word. The other group (OPT-recitation) was told to covertly recite and count a sequence of words from a known position up to the test word in order to place the word in its correct position. They were told to do this as rapidly as they possibly could and to tell $E$ after each placement whether or not they had been able to recite a sequence of words to help place the word in its correct position.

If the OPT-recitation group followed instructions, the latencies across list positions should be sharply bowed towards the middle of the list due to the increased number of words to be counted from the ends toward the middle. If the OPT-position group followed instructions, the latencies across positions should show little bowing since $S$ would use only one cue, a relative position on the spatial array, to place each item. Thus the OPT-position latencies should be shorter than the OPT-recitation latencies, with the difference increasing from the ends of the list towards the middle.

In both the Schulz and the Heslip and Epstein experiments, Ss were tested after different amounts of practice. The test should be a consistent measure both across list positions and over successive degrees of acquisition since it is assumed that $\mathbf{S}$ uses the same dimensional cue throughout learning. To test for consistency over degrees of acquisition, a group of $13 \mathrm{Ss}$ (5 trial-position) was given five trials of practice with the experimental list followed by the position placement task. They were given instructions to place each word immediately by position. If the test measure is consistent and unconfounded, the two position-instruction groups should not differ from each other but they should differ significantly from the recitation-instruction group.

The 39 Ss were volunteers from an introductory psychology course at the University of Kansas.

\section{RESULTS AND DISCUSSION}

Figure 1 shows the average time required by Ss to place the words from each list position on the spatial array. The scores indicate time to place each word, not the accuracy of placement. The recitation group reported that they were able to comply with instructions by reciting a sequence of words to place each item on the board, except of course for the words at the ends of the list.

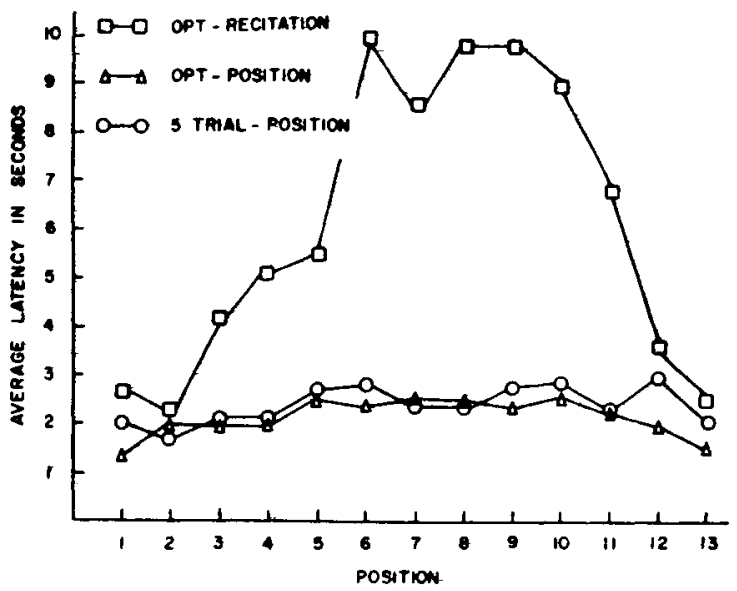

Fig. 1. Average placement latencies for Ss who learned the list to a one-perfeet-trial criterion followed by recitation instructions (OPTrecitation) or by position instructions (OPT-position), and for $\mathbf{S}$ who received five karning trials followed by position instructions (5 trialposition). 
An analysis of variance was performed to generate an error term. There were two factors: Groups and Positions, with repeated measures over positions. Ss were nested in groups. Individual, a priori contrasts were made between pairs of groups. The two position-instruction groups did not differ significantly $(F=0.6 . \mathrm{df}=1 / 36)$. Both the five trial-position and OPT-position groups differed significantly from the OPT-recitation group $(F=96.0$ and 11 1.2. $\mathrm{df}=1 / 36$, $\mathrm{p}<.001)$. A priori contrasts were also made between Positions 1. 2, 12.13 and Positions 6. 7.8,9 within each group in order to test for a serial position effect (SPE). There was no bowing effect for the five trial-position group $(F=1.2$, df $=1 / 432)$. Both OPT groups had significant SPEs: OPT-position group $(F=4.1 . \quad$ df $=1 / 432, \quad p<.05)$. OPT-recitation group $(F=364.4, \mathrm{df}=1 / 432, \mathrm{p}<.001)$.

The OPT-recitation curve in Fig. 1 indicates how long it took to recite a sequence of words to locate the position of each item. A time limit of $3 \mathrm{sec}$ would eliminate the possibility of a recitation confounding in this kind of a test of the position hypotheses: however, a longer time. such as the $15 \mathrm{sec}$ used by Woodward \& Murdock (1968) to test the ordinal-position hypothesis, would allow $S$ ample time to mediate recall by reciting. The fact that latencies were consistent across positions for the position-instruction groups as compared to the recitation group indicates that recitation was eliminated by the position instructions. The similarity of the curves for the two position-instruction groups indicates that this method of testing for the effectiveness of positional cues is consistent for different degrees of list acquisition. It seems, therefore, that the direct method used to test positional mediating cues in the Schulz and in the Heslip and Epstein experiments is a consistent measuring device both across list positions and over different degrees of acquisition: and further, if $S$ is limited in response time to about $3 \mathrm{sec}$ he does not have time to introduce a recitation confounding into the measure.

\section{REFERENCES}

EBENHOLTZ, S. M. Positional cues as mediators in discrimination learning. Journal of Experimental Psychology, 1965, 70, 176-181.

HESLIP, J. R., \& EPSTEIN, W. The effectiveness of serial position and preceding-item cues in serial learning. Journal of Experimental Psy chology, in press.

NOBLE, C. E., \& PARKER, G. V. C. Montana scale of meaningfulness (m). Psychological Reports, 1960, 7, 325-331.

SCHULZ, R. W. Generalization of serial position in rote serial learning. Journal of Experimental Psychology, 1955, 49, 267-272.

WOODWARD, A. E., JR., \& MURDOCK, B. B., JR. Positional and sequential probes in serial learning. Canadian Journal of Psychology, $1968,22,131-138$. 